\title{
CARACTERIZAÇÃO FISIOGRÁFICA DA BACIA HIDROGRAFICA DO RIACHO DO MACHADO EM VÁRZEA ALEGRE, CEARÁ
}

\author{
Characterization physiographic of the watershed of the Machado of \\ Creek in Várzea Alegre, Ceará
}

\begin{abstract}
Geovane Barbosa Reinaldo Costa Graduando em Tecnologia em Irrigação e Drenagem pelo Instituto Federal de Educação, Ciência e Tecnologia, Campus Iguatu. geovanebarbosa09@gmail.com

Helba Araújo de Queiroz Palácio Professora Doutora do Instituto Federal de Educação, Ciência e Tecnologia, Campus Iguatu. helbaraujo23@yahoo.com.br

José Bandeira Brasil Mestrando em Engenharia Agrícola no Departamento de Engenharia Agrícola, CCA/UFC josebbrasil@gmail.com

Matheus Magalhães Silva Moura Graduando em Tecnologia em Irrigação e Drenagem pelo Instituto Federal de Educação, Ciência e Tecnologia, Campus Iguatu. Bolsista de Iniciação Científica da FUNCAP matheusmsm@hotmail.com.br

Marcos Makeison Moreira de Souza Graduando em Tecnologia em Irrigação e Drenagem pelo Instituto Federal de Educação, Ciência e Tecnologia, Campus Iguatu. Bolsista de Iniciação Científica da FUNCAP makeison.moreira14@gmail.com
\end{abstract}

RESUMO: O estudo das características morfométricas é primordial no diagnóstico da susceptibilidade à degradação ambiental, nos quais contribui na gestão de medidas que visem a conservação dos recursos hídricos na bacia hidrográfica. Objetivou-se neste trabalho determinar as características morfométricas da bacia hidrográfica do Riacho do Machado, localizada no município de Várzea Alegre, Ceará, Brasil. Neste sentido, obteve-se inicialmente o Modelo Numérico do Terreno (MNT) da missão SRTM (Missão Topográfica Radar Shuttle), para a estimativa dos principais parâmetros fisiográficos importantes para o estudo do comportamento hidrológico da área delimitada topograficamente, utilizando o sistema de informações geográficas (SIG) ARCGIS 9.3 para o processamento dos dados. Após a delimitação da área, foram obtidas as características físicas, como: área, perímetro, índice de circularidade, coeficiente de compacidade, fator de forma, declividade, altitude, densidade de drenagem e ordem dos cursos d'água. O uso de SIG e dados SRTM, permite a delimitação e caracterização fisiográfica, possibilitando um levantamento rápido e detalhado da bacia. A análise dos dados morfométricos mostrou que a bacia hidrográfica do Riacho do Machado é pouco susceptível a picos de enchentes.

Palavras-chave: Morfometria; SIG; SRTM

ABSTRACT: The study of Morphometric characteristics is paramount in diagnosing susceptibility to environmental degradation, in which it contributes to the management of measures aimed at the conservation of water resources in the watershed. It was aimed at this work to determine the 
CARACTERIZAÇÃO FISIOGRÁFICA DA BACIA HIDROGRAFICA DO RIACHO DO MACHADO EM VÁRZEA ALEGRE, CEARÁ

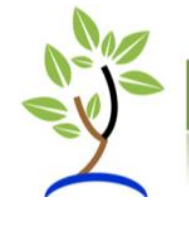

morphometric characteristics of the watershed of the creek of Machado, located in the municipality of Varzea Alegre, Ceará, Brazil. In this sense, it was initially obtained the Digital Terrain Model (DTM) of the mission SRTM (Shuttle Radar Topography Mission), for the estimation of the main parameters physiographic important for the study of the hydrological behavior of the area delimited Topographically, using the Geographic Information System (SIG) ARCGIS 9.3 for data processing. Following the demarcation of the area, the physical characteristics were obtained, such as: area, perimeter, circularity index, compactness coefficient, form factor, slope, altitude, drainage density and water course order. The use of GIS and SRTM data allows the demarcation and physiographic characterization, enabling a rapid and detailed survey of the basin. The analysis of the morphometric data showed that the watershed of the Machado Creek is unlikely to flood peaks.

Keywords: Morphometry; GIS; SRTM.

\section{INTRODUÇÃO}

A análise morfométrica de bacias hidrográficas é definida como um conjunto de procedimentos metodológicos que tem como orientação, a investigação e compreensão cientifica dos componentes naturais de uma bacia hidrográfica (SANTOS et al., 2012, p.617). Conhecer o ambiente físico é essencial para subsidiar o processo de ocupação e manejo das bacias hidrográficas, reconhecendo áreas de fragilidade natural e potencializadas pelo antropismo, sendo assim, conhecer as características morfométricas e físicas de uma unidade geoambiental permite o planejamento da ocupação do espaço de maneira mais sustentável (ALVES et al., 2014, p.131). Segundo Vasco et al. (2011, p.119), o estudo das bacias hidrográficas, tanto urbanas quanto rurais, é imprescindível para obter o equilíbrio entre a exploração dos recursos naturais e a sustentabilidade ambiental.

As características físicas e bióticas de uma bacia possuem importante papel nos processos do ciclo hidrológico, influenciando, dentre outros, a infiltração, a quantidade de água produzida como deflúvio, a evapotranspiração, os escoamentos superficial e sub-superficial (TEODORO et al., 2007, p.142). Conforme Santos et al. (2017, p. 684), a erosão em bacias hidrográficas tem causas relacionadas com o próprio ambiente, como, declividade, comprimento e forma das encostas. Para Rodrigues et al. (2010, p.6) o estudo da declividade permite entender a energia de transporte, velocidade do fluxo de água, profundidade do canal e, consequentemente compreender a dinâmica do ambiente fluvial.

No planejamento de recursos naturais, têm sido utilizadas ferramentas digitais para aquisição, análise e divulgação de informações espaciais, como os Sistemas de Informações Geográficas (SIGs), pois a principal característica destes é focalizar o relacionamento de determinado fenômeno da realidade com sua localização espacial (CAMPOS, et al., 2015, p.34). Além disso, Santiago et al. (2015, p.403) afirmam que o uso de SIG possibilita maior rapidez e precisão quanto aos resultados no que se refere à análise dos elementos físicos do ambiente, em especial, o estudo morfométrico, permitindo maior agilidade nas tomadas de decisão.

Portanto, objetivou-se neste trabalho obter os parâmetros morfométricas da bacia hidrográfica do Riacho do Machado, utilizando o software ArcMap 9.3 e dados SRTM. 
CARACTERIZAÇÃO FISIOGRÁFICA DA BACIA HIDROGRAFICA DO RIACHO DO MACHADO EM VÁRZEA ALEGRE, CEARÁ

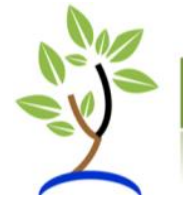

\section{MATERIAL E MÉTODOS}

\section{Localização e caracterização da área em estudo}

A bacia hidrográfica do Riacho do Machado está localizada na sub-bacia do Salgado, mais precisamente no município de Várzea Alegre no estado do Ceará, Brasil (Figura 1), com latitude de $6^{\circ} 42^{\prime} 33^{\prime \prime}$ e $6^{\circ} 55^{\prime} 17^{\prime \prime} \mathrm{S}$ e as longitudes $39^{\circ} 12^{\prime} 21^{\prime \prime}$ e $39^{\circ} 23^{\prime} 43^{\prime \prime} \mathrm{W}$. Segundo a classificação climática de Köppen (1948, p.259), é do tipo BSw'h', (tropical quente semiárido), de temperatura média anual de 26 a $28{ }^{\circ} \mathrm{C}$ e altura pluviométrica média anual de 965,3 mm (IPECE, 2016, p.5).

A vegetação é basicamente formada por Caatinga Arbustiva Densa, Cerrado, Floresta Caducifólia Espinhosa e Floresta Subcaducifólia Tropical Pluvial. A área em estudo é caracterizada pelas unidades geomorfológicas Depressões Sertanejas e Maciços Residuais. Diversos solos são encontrados na região, Solos Aluviais, Solos Litólicos e Podzólicos Vermelho-Amarelos (IPECE, 2016, p.5).

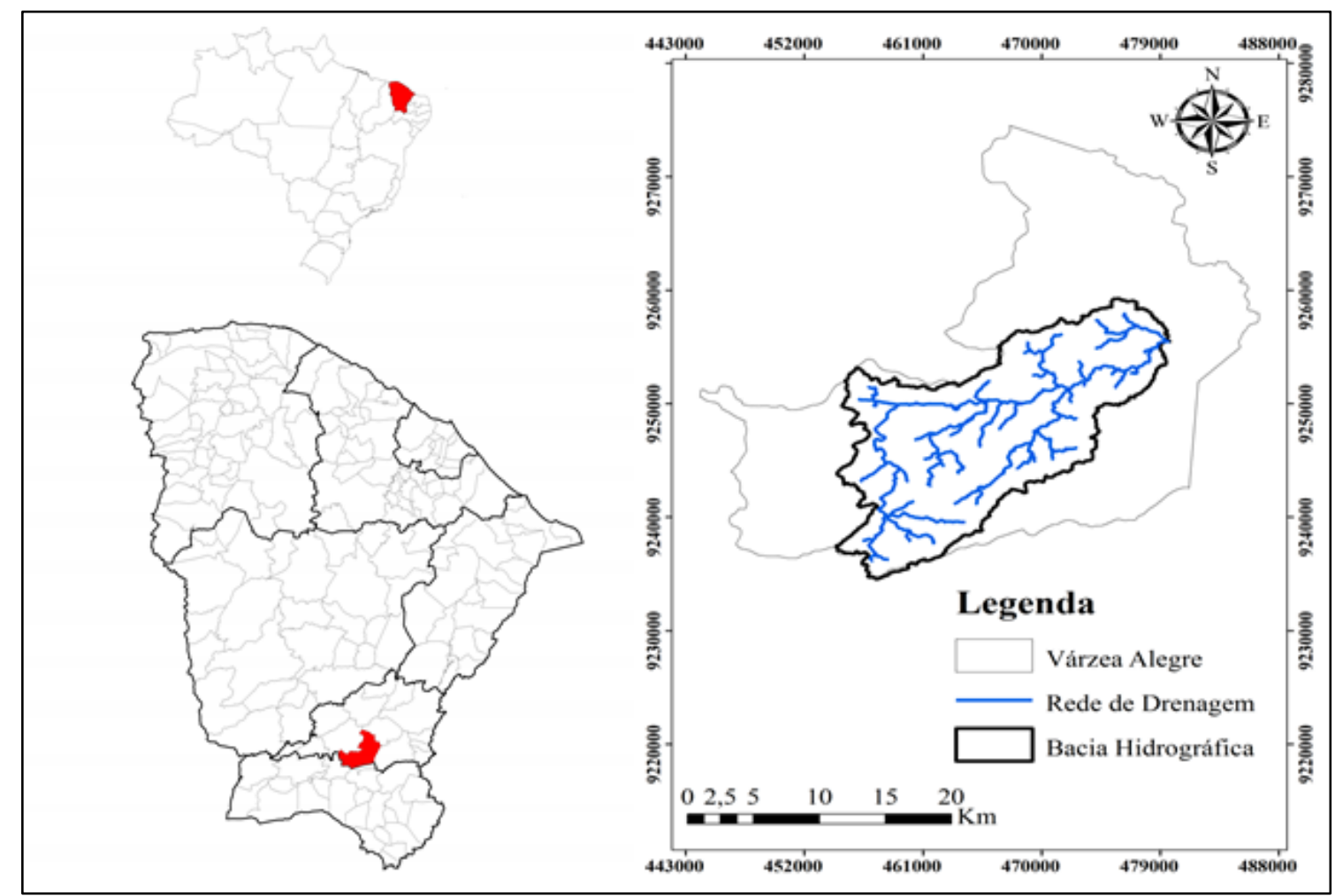

Figura 1. Área de estudo localizada no município de Várzea Alegre, Ceará.

\section{Processos para a delimitação automática}

Para a delimitação da bacia Riacho do Machado foi utilizado o software ArcMap 9.3 e dados SRTM (Shuttle Radar Topography Mission). Para executar a delimitação automática, primeiramente foram adquiridos dados SRTM, com resolução espacial de 30 × 30 m, junto ao United States Geological Survey (USGS) da região de estudo. Estes dados foram processados no software Global Mapper 11.0, a partir de 4 imagens foi criado um mosaico da região de interesse e este foi salvo em formato 
CARACTERIZAÇÃO FISIOGRÁFICA DA BACIA HIDROGRAFICA DO RIACHO DO MACHADO EM VÁRZEA ALEGRE, CEARÁ

\section{留}

ASCII. Na sequência, este arquivo ASCII foi adicionado no software ArcMap 9.3, sendo convertido para um formato raster, no qual posteriormente foi processado para a delimitação da bacia. A metodologia utilizada neste processamento foi subdivida nas seguintes etapas: 1) preenchimento de erros (Fill Sinks) corrigindo o MDE; 2) direção de fluxo (Flow Direction); 3) fluxo acumulado (Flow Accumulation); 4) definição de fluxo (Stream Definition) adotando-se valor 1000 como o número mínimo de células para a geração de fluxo; 5) segmentação de fluxo (Stream Segmentation); 6) delimitação da rede de capitação (Catchment Grid Delineation); 7) processamento dos polígonos de capitação (Catchment Polygon Processing); 8) processamento da rede de drenagem (Drainage Line Processing); 9) processamento de captação adjunto (Adjoint Catchment Processing); 10) processamento de pontos de drenagem (Drainage Point Processing); 11) geração de lotes de pontos (Batch Point Generation); e 12) delimitação da bacia hidrográfica (Watershed).

\section{Caracterização morfométrica da bacia}

Depois de delimitada a bacia hidrográfica, foi criada um shape do limite da bacia com a ferramenta Raster to Features da extensão Spatial Analyst. Com este arquivo vetorial do limite da bacia foram calculadas na extensão Xtools Pro a área e o perímetro da bacia. Com base nesta bacia delimitada automaticamente, foram determinados o comprimento do rio principal usando a ferramenta Longest Flow Patch da extensão Archydro; o comprimento da bacia (comprimento de uma linha traçada paralela ao rio principal); a hierarquia fluvial pelo método de Strahler (classificando automaticamente com as ferramentas Stream Link, Stream Order e Stream To Feature); a declividade do canal principal, que foi determinada pela razão entre as altitudes nas extremidades do canal principal (medidas no MDE) pelo seu comprimento; a declividade da bacia, que foi determinada usando a ferramenta Slope da extensão 3D Analyst e classificada conforme a Tabela 1 (EMBRAPA, 1979, p.27).

Tabela 1. Classificação da declividade conforme (EMBRAPA, 1979, p.27).

\begin{tabular}{lll}
\hline Declividade (\%) & Discriminação & $\%$ \\
\hline $0-3$ & Relevo plano & 11,82 \\
$3-8$ & Relevo suavemente ondulado & 24,82 \\
$8-20$ & Relevo ondulado & 48,20 \\
$20-45$ & Relevo fortemente ondulado & 14,23 \\
$45-75$ & Relevo montanhoso & 0,92 \\
$>75$ & Relevo fortemente montanhoso & 0,00 \\
\hline
\end{tabular}

\section{Fator de forma $\left(\mathrm{K}_{\mathrm{f}}\right)$}

A relação entre a área da bacia e o comprimento bacia quando se segue o curso d'água mais longo, é definido como o fator de forma da bacia hidrográfica, dado por (VILLELA \& MATTOS, 1975, p.14) conforme a seguinte equação: 
CARACTERIZAÇÃO FISIOGRÁFICA DA BACIA HIDROGRAFICA DO RIACHO DO MACHADO EM VÁRZEA ALEGRE, CEARÁ

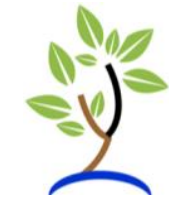

$\mathrm{K}_{\mathrm{f}}=\frac{\mathrm{A}}{\mathrm{C}^{2}}$

Onde: $\mathrm{K}_{\mathrm{f}}$ - fator de forma; $\mathrm{A}$ - área de drenagem $\left(\mathrm{km}^{2}\right) ; \mathrm{C}$ - comprimento do eixo da bacia $(\mathrm{km})$.

\section{Índice de circularidade (IC)}

Simultaneamente ao coeficiente de compacidade, o índice de circularidade tende para unidade à medida que a bacia aproxima-se a forma circular e diminui à medida que a forma torna alongada, segundo a equação (CARDOSO et al., 2006, p.244):

IC $=\frac{12,57 \times A}{P^{2}}$

Onde: Ic - índice de circularidade; $\mathrm{A}$ - área de drenagem $\left(\mathrm{km}^{2}\right) ; \mathrm{P}$ - perímetro $(\mathrm{km})$.

Quando os valores do fator de forma e o índice de circularidade próximos ou igual a 1,0, a bacia possui alta tendência a enchentes, por apresentar formato circular, diminuindo à medida que a forma se torna comprida, de acordo com a Tabela 2.

Tabela 2. Valores e a interpretação dos resultados quanto ao: fator de forma $\left(\mathrm{K}_{\mathrm{f}}\right)$, índice de circularidade $\left(I_{c}\right)$ e, coeficiente de compacidade $\left(K_{c}\right)$ da bacia.

\begin{tabular}{|c|c|c|c|c|}
\hline$K_{f}$ & $\mathrm{I}_{\mathrm{C}}$ & $\mathrm{K}_{\mathrm{c}}$ & Formato & $\begin{array}{l}\text { Interpretação ambiental da } \\
\text { bacia }\end{array}$ \\
\hline $1,00-0,75$ & $1,00-0,8$ & $1,00-1,25$ & Redonda & alta tendência a enchentes \\
\hline $0,75-0,50$ & $0,8-0,6$ & $1,25-1,50$ & Ovalada & tendência mediana a enchentes \\
\hline $0,50-0,30$ & $0,6-0,40$ & $1,50-1,70$ & Oblonga & baixa tendência a enchentes \\
\hline$<0,30$ & $<0,40$ & $>1,70$ & Comprida & $\begin{array}{l}\text { bacia com tendência } \\
\text { conservação }\end{array}$ \\
\hline
\end{tabular}

Adaptado da fonte: Villela \& Mattos (1975, p.14).

\section{Coeficiente de Compacidade $\left(\mathrm{K}_{\mathrm{c}}\right)$}

Após a bacia de drenagem ser limitada, ela apresenta um formato que influência no tempo de concentração, ou seja, no tempo decorrido pela água a partir dos limites da bacia até a sua secção de controle. Para determinação da forma da bacia, os índices relacionam a bacia com formas geométricas comuns. O coeficiente de compacidade é a relação entre o perímetro da bacia e um círculo de área igual à da bacia (VILLELA \& MATTOS, 1975, p.13):

$\mathrm{Kc}=0,28 \frac{\mathrm{P}}{\sqrt{\mathrm{A}}}$

Onde: $\mathrm{Kc}$ - coeficiente de compacidade; $\mathrm{P}$ - perímetro $(\mathrm{km}) ; \mathrm{A}$ - área de drenagem $\left(\mathrm{km}^{2}\right)$.

Quanto mais o coeficiente de compacidade da unidade, mais a bacia se assemelha a um círculo. $O$ formato e a interpretação dos resultados podem ser observados na Tabela 2. 
CARACTERIZAÇÃO FISIOGRÁFICA DA BACIA HIDROGRAFICA DO RIACHO DO MACHADO EM VÁRZEA ALEGRE, CEARÁ

\section{Densidade de drenagem $\left(D_{d}\right)$}

Segundo Lima (1986, p.52), a densidade de drenagem reflete a influência da geologia, topografia, solo e vegetação da bacia hidrográfica, e está relacionada com o tempo gasto para a saída do escoamento superficial da bacia. A densidade de drenagem é a relação entre o comprimento total dos cursos d'água de uma bacia hidrográfica, sejam eles intermitentes ou perenes, e a área total da bacia, definida por (HORTON, 1945, p.284):

$\mathrm{Dd}=\frac{\mathrm{Cr}}{\mathrm{A}}$

Onde: $\mathrm{Dd}$ - densidade de drenagem; $\mathrm{Cr}$ - comprimento da rede de drenagem (km); A - área de drenagem $\left(\mathrm{km}^{2}\right)$.

\section{Índice de sinuosidade (Is)}

A sinuosidade de uma bacia hidrográfica representa a relação entre o comprimento principal e o comprimento do talvegue, conforme a equação a seguir:

$I_{s}=\frac{C p}{C t}$

Onde: Is - sinuosidade do curso d'água; $\mathrm{Cp}$ - comprimento do rio principal $(\mathrm{km}) ; \mathrm{Ct}-$ comprimento do talvegue $(\mathrm{km})$.

\section{Hierarquia da Rede de Drenagem}

A ordem dos canais de rede de drenagem pode ser determinada seguindo os critérios introduzidos por Horton (1945, p.281) e Strahler (1957, p.15). Neste trabalho a classificação utilizada seguiu o princípio apresentado por Strahler, em que os canais sem tributários são designados de primeira ordem. Os canais de segunda ordem são os que se originam da confluência de dois canais de primeira ordem, podendo ter afluentes também de primeira ordem. Os canais de terceira ordem originam-se da confluência de dois canais de segunda ordem, podendo receber afluentes de segunda e primeira ordens, e assim sucessivamente (SILVEIRA, 2001, p.42).

\section{RESULTADOS E DISCUSSÃO}

A área de drenagem da bacia do Riacho do Machado é de $303,25 \mathrm{~km}^{2}$ e perímetro de 141,12 km (Tabela 3). Conforme a Tabela 2, a bacia hidrográfica possui pouca susceptibilidade a enchentes, quanto a sua forma. 
CARACTERIZAÇÃO FISIOGRÁFICA DA BACIA HIDROGRAFICA DO RIACHO DO MACHADO EM VÁRZEA ALEGRE, CEARÁ

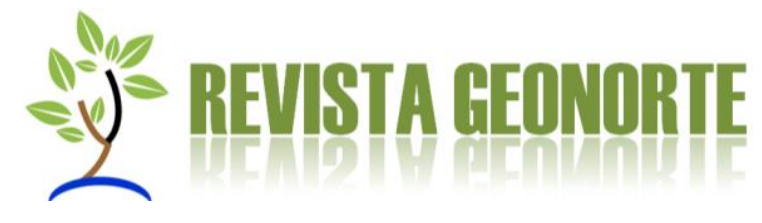

Tabela 3 - Características físicas da bacia hidrográfica do Riacho do Machado.

\begin{tabular}{lll}
\hline \multicolumn{1}{c}{ Características Físicas } & Unidades & Resultados \\
\hline Área da bacia & $\mathrm{km}^{2}$ & 303,25 \\
Perímetro da bacia & $\mathrm{km}$ & 141,12 \\
Comprimento do curso principal & $\mathrm{km}$ & 51,47 \\
Comprimento da bacia & $\mathrm{km}$ & 31,02 \\
Coeficiente de compacidade & - & 2,27 \\
Fator de forma & - & 0,32 \\
Hierarquia fluvial (Strahler) & - & $4^{\mathrm{a}}$ \\
Sinuosidade do curso principal da bacia & - & 2,32 \\
Densidade de Drenagem & $\mathrm{km} / \mathrm{km}^{2}$ & 0,58 \\
Índice de Circularidade & - & 0,19 \\
Talvegue & $\mathrm{km}$ & 22,16 \\
Altitude mínima & $\mathrm{m}$ & 278,00 \\
Altitude média & $\mathrm{m}$ & 382,24 \\
Altitude máxima & $\mathrm{m}$ & 671,00 \\
Declividade média & $\%$ & 12,16 \\
Declividade máxima & $\%$ & 79,26 \\
\hline
\end{tabular}

O fator de forma de 0,32, o índice de circularidade com valor de 0,19, e o coeficiente de compacidade de 2,27, apresentaram as mesmas condições. Esses resultados demonstram que a bacia possui geometria alongada (Tabela 2), sendo assim, menor concentração do deflúvio, conforme Villela e Mattos (1975, p.14). Zanata et al. (2011, p. 1065) afirmam que quanto menor o risco a grandes enchentes acentuadas, também será menor o risco de assoreamentos dos cursos d'água, consequentemente, a degradação ambiental da rede de drenagem diminuirá.

O sistema de drenagem de uma bacia é constituído pelo rio principal e seus tributários, o estudo das ramificações e do desenvolvimento do sistema é importante, pois ele indica a maior ou menor velocidade com que a água deixa a bacia hidrográfica. A densidade de drenagem de $0,58 \mathrm{~km} / \mathrm{km}^{2}$, indica que a bacia hidrográfica do Riacho do Machado é de drenagem regular. Segundo Villela e Mattos (1975, p.16) bacias com valores menores que $0,5 \mathrm{~km} / \mathrm{km}^{2}$ são consideradas com drenagem pobre, valores da entre 0,5 e $1,5 \mathrm{~km} / \mathrm{km}^{2}$ são de drenagem regular, de 1,5 e $2,5 \mathrm{~km} / \mathrm{km}^{2}$ caracterizam uma bacia de drenagem boa, entre 2,5 e $3,5 \mathrm{~km} / \mathrm{km}^{2}$ drenagem muito boa e, por fim, valores acima de 3,5 caracterizam bacias excepcionalmente bem drenadas.

O Índices de Sinuosidade na bacia do Riacho do Machado indica que seu canal principal tende a ser tortuoso, pois valores próximos a 1 indicam canais com tendências retilíneas enquanto valores superiores a 2 sugerem canais tortuosos. $O$ método de Strahler (1964, p.447) foi utilizado nesse estudo para a classificação fisiográfica da drenagem, assim, de acordo com sua hierarquização da rede de 
CARACTERIZAÇÃO FISIOGRÁFICA DA BACIA HIDROGRAFICA DO RIACHO DO MACHADO EM VÁRZEA ALEGRE, CEARÁ

drenagem, a bacia apresentou ser de $4^{a}$ ordem, demonstrando assim uma ramificação significativa, considera-se que, quanto mais ramificada for à rede, mais eficiente será o sistema de drenagem.

Para a declividade do terreno da bacia, verifica-se a predominância das classes de relevo ondulado e suavemente ondulado, conforme a classificação da EMBRAPA (1979, p.27), com valores de percentagem 48,20 \% e 24,82 \% da área total da bacia, respectivamente (Figura 2). A declividade média de uma bacia hidrográfica exerce um papel fundamental no processo da geração de escoamento superficial e subsuperficial. A ausência de cobertura vegetal, classe de solo, intensidade de chuvas, dentre outros, associada à maior declividade, conduzirá à maior velocidade de escoamento, menor quantidade de água armazenada no solo e resultará em enchentes mais pronunciadas, sujeitando a bacia à degradação (TONELLO, 2005, p.30).

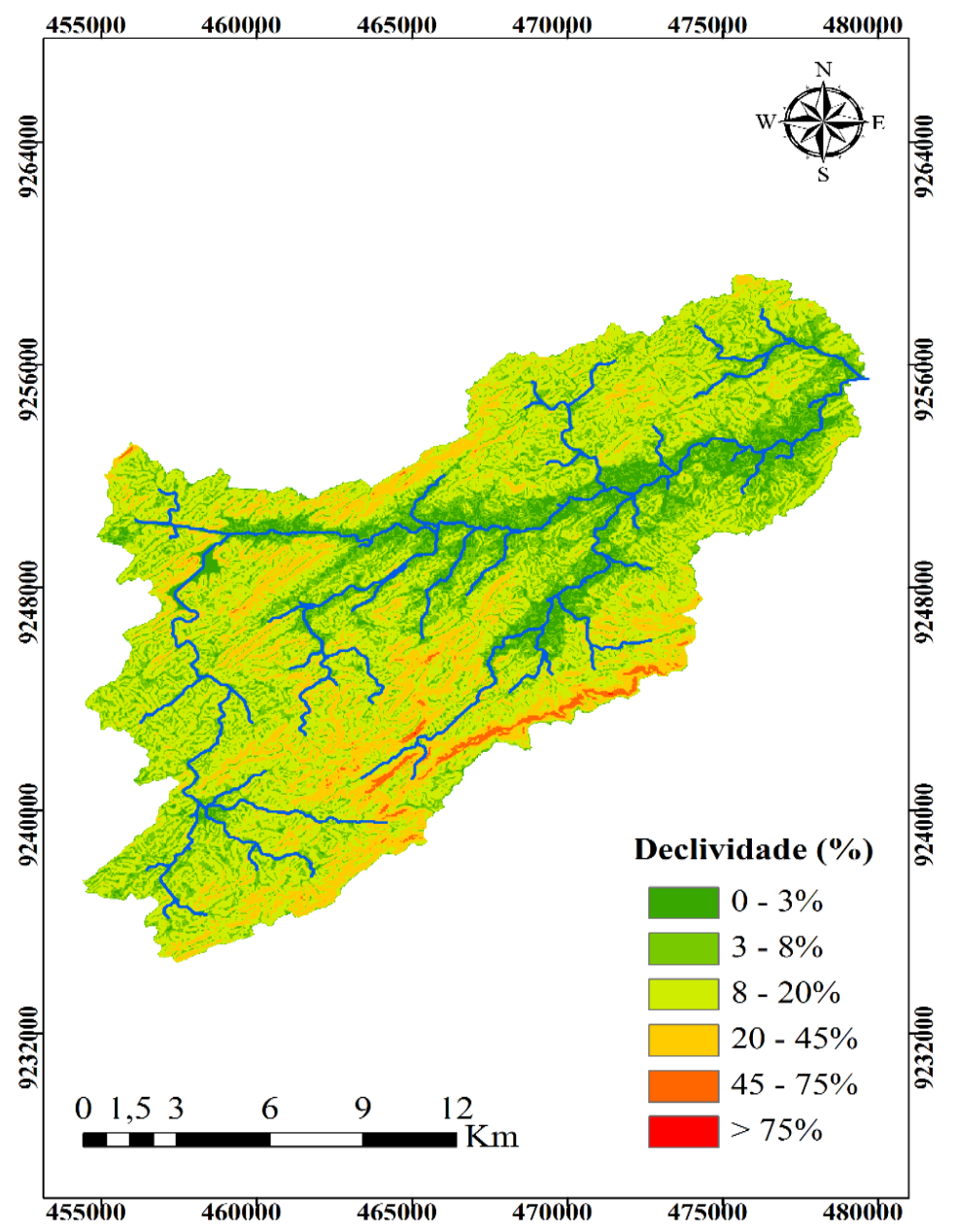

Figura 2. Mapa de declividade da Bacia Hidrográfica do Riacho do Machado.

A declividade média de uma bacia hidrográfica é relevante no planejamento, tanto para com o cumprimento da legislação quanto para garantir a eficiência das intervenções do homem no meio e possui importante papel na distribuição da água 
CARACTERIZAÇÃO FISIOGRÁFICA DA BACIA HIDROGRAFICA DO RIACHO DO MACHADO EM VÁRZEA ALEGRE, CEARÁ

entre o escoamento superficial e subterrâneo, dentre outros processos. Compreender o comportamento das precipitações em relação à declividade visa o tempo que o curso d'água leva a água dos limites da bacia para chegar ao exutório (TONELLO et al., 2006, p.853). Com o índice morfométrico de desnivelamento é possível revelar a grande tendência das bacias hidrográficas em gerar fluxos intensos e de grande velocidade em seus cursos d'água, auxiliando a compreender melhor a velocidade que os fluxos adquirem nos canais fluviais, assim como a sua capacidade corrosão (MARINS et al., 2014, p.182).

A Figura 3 mostra o comportamento espacial da altitude, com máxima de $671 \mathrm{~m}$, mínima de 278 m e média de $382 \mathrm{~m}$. Para Duarte et al. (2008, p.60), a variação da elevação e a elevação média de uma bacia hidrográfica tem grande correlação com a temperatura e a precipitação.

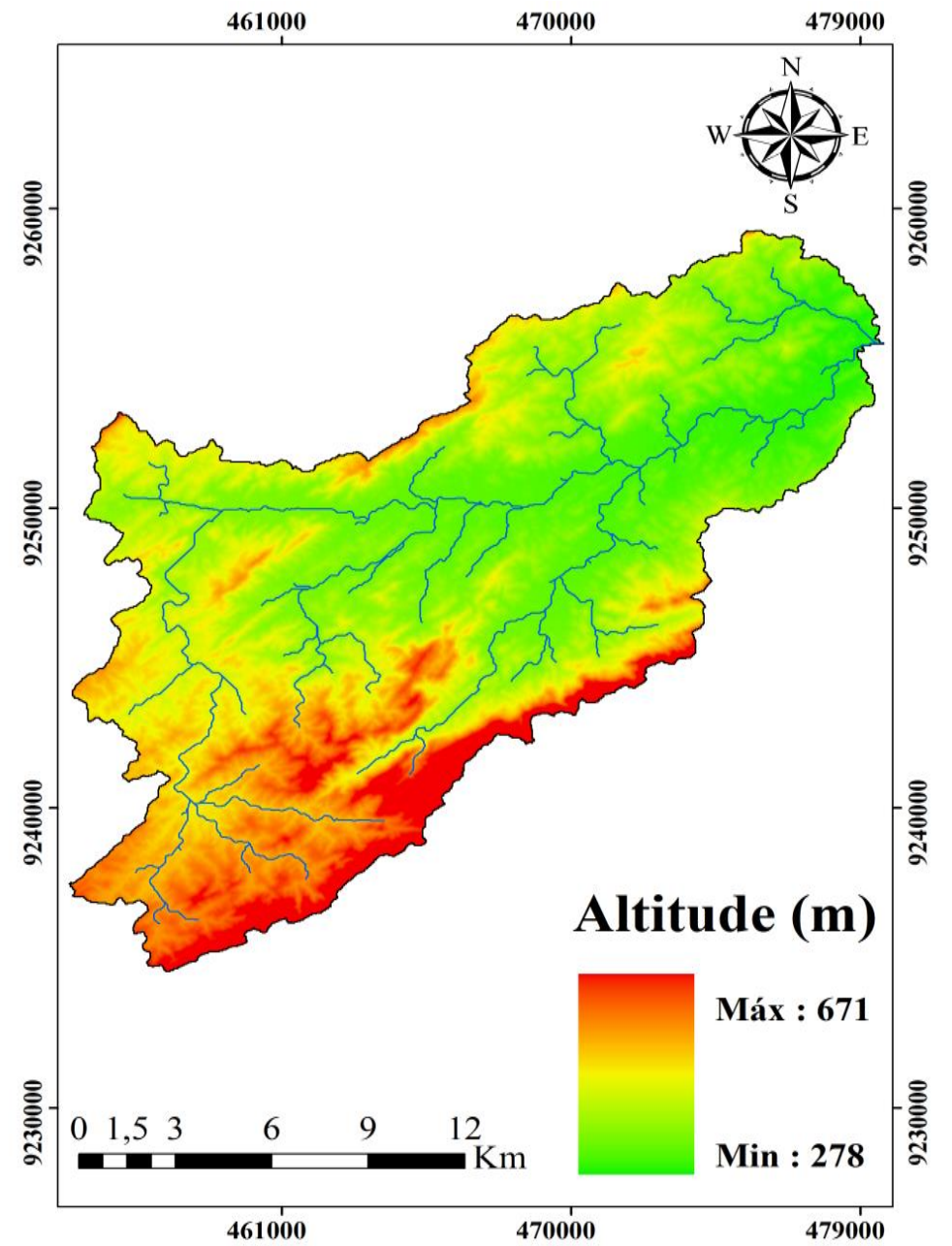

Figura 3. Mapa de altimetria da Bacia Hidrográfica do Riacho do Machado.

Segundo Teodoro et al. (2007, p.149), a variação de altitude associasse com a precipitação, evaporação e transpiração, consequentemente sobre o deflúvio médio, e que grandes variações de altitude numa bacia acarretam diferenças significativas na temperatura média, a qual, por sua vez, causa variações na evapotranspiração. 
CARACTERIZAÇÃO FISIOGRÁFICA DA BACIA HIDROGRAFICA DO RIACHO DO MACHADO EM VÁRZEA ALEGRE, CEARÁ

\section{泟}

Mais significativas, porém, são as possíveis variações de precipitação anual com a elevação (TEODORO et al., 2007, p.149).

As informações oriundas dos parâmetros morfométricos como os desta pesquisa são de grande valia à gestão de bacias hidrográficas na medida em que fornecem os referenciais básicos para o conhecimento do sistema em questão e dão subsídios para um melhor direcionamento das ações de planejamento e utilização racional dos seus recursos (SANTOS et al., 2012, p.12). Diante desse tipo de caracterização, observa-se a necessidade de ações que visem à restauração florestal de áreas prioritárias e críticas, uma vez que as condições físicas atreladas ao uso agrícola que Ihe é dado podem interferir na dinâmica hidrológica da bacia (SILVA; TONELLO, 2014, p.109)

Sendo assim, torna-se importante a prevenção quanto a degradação antrópica, que influencia nos processos erosivos e altera a formação original do solo não deixando a sua recuperação natural. Isso acontece quando se desconhecem as propriedades do solo, uma vez que possuem fragilidades diferenciadas à erosão, que, acrescidas a outros fatores, como declividade do terreno e aspectos climáticos, aumentam ainda mais a fragilidade dos mesmos (RIBEIRO et al., 2014, p.153). Por isso, conhecer as características morfométricas de uma bacia hidrográfica é imprescindível à conservação de seus recursos hídricos, pois possibilita a compreensão do comportamento hidrológico que a mesma apresenta e que futuramente poderá vir a apresentar, o que permite o acompanhamento das interferências nos processos do ciclo hidrológico e as respectivas respostas da natureza (FERREIRA et al., 2012, p.2248).

\section{CONCLUSÕES}

A bacia hidrográfica do Riacho do Machado é pouco susceptível a enchentes, devido a forma alongada e o sistema de drenagem da bacia, sendo comprovado pelo índice de circularidade, coeficiente de compacidade, fator de forma e densidade de drenagem.

O uso de SIG e de dados SRTM, permite a delimitação e caracterização fisiográfica de bacias hidrográficas. Além de compreender cada característica da bacia, pois estas podem influenciar no comportamento hidrológico e nas condições ambientais.

\section{AGRADECIMENTOS}

Os autores agradecem ao CNPq e a FUNCAP pelo apoio financeiro e pelas bolsas de produtividade e iniciação científica. 
CARACTERIZAÇÃO FISIOGRÁFICA DA BACIA HIDROGRAFICA DO RIACHO DO MACHADO EM VÁRZEA ALEGRE, CEARÁ

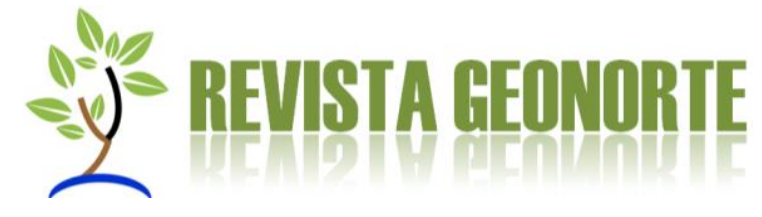

\section{REFERÊNCIAS}

ALVES, T. L. B.; AZEVEDO, P. V.; SILVA, M. T. Análise morfométrica da bacia hidrográfica riacho Namorado, São João do Cariri-PB: uma ferramenta ao diagnóstico físico. Revista de Geografia (UFPE), v. 31, n. 3, p.130-148, 2014.

CAMPOS, S; SILVA, A. M; CARREGA, E. F. B. Sistema de Informações Geográficas Aplicado na Caracterização Morfométrica de uma microbacia hidrográfica. Geotecnologia Aplicada no Planejamento Ambiental de Bacias. Tupã/SP: ANAP, 2015. p. (199)

CARDOSO, C. A.; TEIXEIRA, D. H. C., BOECHAT, S. C. P.; MARTINS, S. V. Caracterização morfométrica da bacia hidrográfica do rio Debossan, Nova Friburgo, RJ. Revista Árvore, v.30, n.2, p.241-248, 2006.

DUARTE, C. C.; GALVÍNCIO, J. D.; CORRÊA D. B.; A. C.; ARAÚJO, M. D. S. B. Análise fisiográfica da bacia hidrográfica do Rio Tapacurá-PE. Revista de Geografia, Recife, v.24, n.2, p.50-64, 2008

EMPRESA BRASILEIRA DE PESQUISA AGROPECUÁRIA - EMBRAPA. Serviço Nacional de Levantamento e Conservação de Solos (Rio de Janeiro, RJ). Súmula da 10. Reunião Técnica de Levantamento de Solos. Rio de Janeiro, 1979, (p.83)

FERREIRA, R. G.; OLIVEIRA, M. M. C.; SILVEIRA, C. F. Caracterização morfométrica da sub-bacia do Ribeirão Panquinhas, ES. Enciclopédia Biosfera, Goiânia, GO, v. 8, n. 15, p. 2247-2256, 2012.

HORTON, R.E. Erosional development of streams and their drainage basins: hydrophysical approach to quantitative morphology. Geological. Society America Bulletin, v. 56, n.3, p.275-370, 1945.

IPECE. Perfil básico municipal, Varzea Alegre, 2016. Disponível em: $<$ www.jpece.ce.gov.br> acessado em 20/10/2017

LIMA, W.D.P. Princípios de hidrologia florestal para o manejo de bacias hidrográficas. In: Princípios de hidrologia florestal para o manejo de bacias hidrográficas. São Paulo: USP, 1986. p. (242).

MARINS, L. S.; COSTA, F. H. L.; LEÃO, O. M. R. Caracterização da bacia do rio Sapê a partir de índices morfométricos: Subsídios geomorfológicos para compreender a ocorrência de enchentes. Revista Geonorte, v.5 n.20 p.181-185, 2014.

KÖPPEN, W. Climatologia: con un estudio de los climas de la tierra. Ciudad de México: Fondo de Cultura Económica, 1948. p. (479). 
CARACTERIZAÇÃO FISIOGRÁFICA DA BACIA HIDROGRAFICA DO RIACHO DO MACHADO EM VÁRZEA ALEGRE, CEARÁ

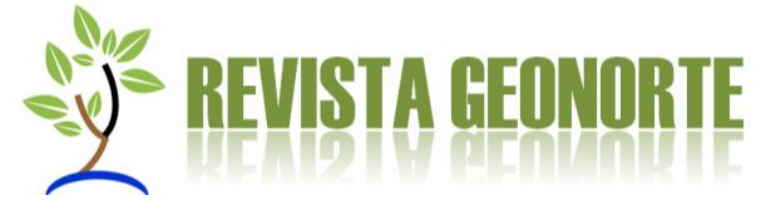

RIBEIRO, J. C.; TOCANTINS, N.; FIGUEIREDO, M. Diagnóstico dos processos erosivos na sub-bacia do córrego Guanabara, município de reserva do Cabeçal/Pantanal/. Revista GeoPantanal,v.8, n.14, p.152-169, 2014.

RODRIGUES, A. S. L; CASTRO, P. T. A; MALAFAIA, G. Utilização dos Protocolos de Avaliação Rápida de Rios como Instrumentos Complementares na Gestão de Bacias Hidrográficas Envolvendo Aspectos da Geomorfologia Fluvial: Uma Breve Discussão. Enciclopédia Biosfera, vol. 6. Goiânia, GO. Centro Científico Conhecer, 2010.

SANTIAGO, C. M. C; GOMES, L. C. F; SALES, M. C. L; Abreu Paula, J. E. Arranjo Espacial da Bacia Hidrográfica do Rio São Nicolau-Piauí a partir da Análise Morfométrica e dos Aspectos Ambientais. Revista Brasileira de Geografia Física, v. 8, n. 2, p. $402-421,2015$.

SANTOS, D. A. R; MORAIS, F. Análise morfométrica da bacia hidrográfica do rio lago verde como subsídio à compartimentação do relevo da região de lagoa da confusãoTO. Revista Geonorte, v.3, n.6, p.617-629, 2012.

SANTOS, D. D.; SILVA, C. B.; CABRAL, J. F. Análise do uso e ocupação das terras em pequenas bacias hidrográficas do semiárido alagoano: riachos da Torta e do Mel no alto curso do Rio Traipú. Os Desafios da Geografia Física na Fronteira do Conhecimento, v.1 n.2017, p.679-686, 2017.

SANTOS, D. B.; VIDOTTO, M. L.; BERTINATTO, R.; MARCON, S G. R.; FRIGO, E. P. Caracterização morfométrica da bacia hidrográfica do Rio São José, Cascavel, PR. Revista Brasileira de Tecnologia Aplicada nas Ciências Agrárias, Guarapuava, v.5, n.2, p.7-18, 2012.

SILVA, J. L.; TONELLO, K. C. Morfometria da bacia hidrográfica do Ribeirão dos Pinheirinhos, Brotas-SP. Revista Irriga, v.19 n.1 p.103 -114, 2014.

SILVEIRA, A. L. L. Ciclo hidrológico e bacia hidrográfica. In: TUCCI, C.E.M. (Org.).Hidrologia: ciência e aplicação. São Paulo: EDUSP, p. 35 - 51.2001.

STRAHLER, A. N. Quantitative analysis of watershed geomorphology. Transaction of American Geophysical Union, v.38, n.6 p. 913-920, 1957.

STRAHLER, A. Quantitative Geomorphology of Drainage Basins and Channel Networks. In: Chow, V., Ed., Handbook of Applied Hydrology, McGraw Hill, New York, v.10, n.5, p. 439-476, 1964.

TEODORO, V. L. I.; TEIXEIRA, D.; COSTA, D. J. L.; FULLER, B. B. O conceito de bacia hidrográfica e a importância da caracterização morfométrica para o entendimento da dinâmica local. Revista UNIARA, v.11, n. 1, p. 137-156, 2007.

TONELLO, K.C. Análise hidroambiental da bacia hidrográfica da cachoeira das 
CARACTERIZAÇÃO FISIOGRÁFICA DA BACIA HIDROGRAFICA DO RIACHO DO MACHADO EM VÁRZEA ALEGRE, CEARÁ

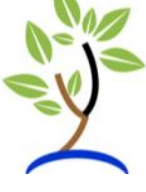

Pombas, Guanhães, MG. 2005. Tese (Doutorado em Ciências Florestal) Universidade Federal de Viçosa, Viçosa, 2005. 85f.

TONELLO, K. C.; DIAS, H. C. T., SOUZA, A. L. D.; RIBEIRO, C. A. A. S.; LEITE, F. P. Morfometria da bacia hidrográfica da Cachoeira das Pombas, Guanhães - MG. Revista Árvore, Viçosa, v.30, n.5, p.849-857, 2006.

VILLELA, S. M.; MATOS, A. Hidrologia aplicada. 1 ed. São Paulo: McGraw-Hill do Brasil, 1975. p. (245)

VASCO, A. N. D.; BRITTO, F. B., PEREIRA, A. P. S.; JÚNIOR, M.; VIEIRA, A.; GARCIA, C. A. B.; NOGUEIRA, L. C. Avaliação espacial e temporal da qualidade da água na sub-bacia do Rio Poxim, Sergipe, Brasil. Revista Ambiente \& Água, Taubaté, v.6, n.1, p.118-130, 2011.

ZANATA, M.; PISSARA, T. C.; ARRAES, C. L.; RODRIGUES, F. M.; CAMPOS, S. Influência da escala na análise morfométrica de microbacias hidrográficas. Revista Brasileira de Engenharia Agrícola e Ambiental, Campina Grande, PB, v.15, n.10, p.1062-1067, 2011. 